\title{
Development of new renal scars: a collaborative study
}

\author{
J M SMELLIE, P G RANSLEY, I C S NORMAND, N PRESCOD, D EDWARDS
}

\begin{abstract}
In a study of the factors surrounding the development of renal scars clinical data and serial radiographs were analysed in 74 infants and children (66 girls and eight boys) without duplex kidney or obstruction. The development of new scars was seen radiologically in 87 kidneys ( 74 previously normal and 13 previously scarred). New scarring was extensive in 16 kidneys. Thirty four children were aged 5 or over when scarring occurred. Urinary infection occurred in all the children. Diagnosis and effective treatment were delayed in 45 of them; 58 suffered further urinary infections between the baseline intravenous urogram and the first showing new scarring. Vesicoureteric reflux was seen in 67 of the children. Investigation and treatment varied widely, and few children received long term prophylaxis. Social problems interfered with the management of 22 children.

Early diagnosis, prompt effective treatment, investigation, and long term supervision of children with urinary infection are essential if renal scarring is to be reduced; those over the age of 5 are still vulnerable.
\end{abstract}

\section{University College Hospital, London WC1E 6AU}

J M SMELLIE, DM, FRCP, senior lecturer in paediatrics and honorary consultant paediatrician

N PRESCOD, BSC, research assistant

D EDWARDS, FRCP, FRCR, director, department of radiology

The Hospitals for Sick Children, Great Ormond Street, London WC1

P G RANSLEY, FRCs, consultant paediatric urological surgeon

University of Southampton, Southampton

I C S NORMAND, DM, FRCP, professor of child health

Correspondence to: Dr J M Smellie.

\section{Introduction}

The coarse renal scarring of chronic atrophic pyelonephritis (reflux nephropathy) is found in $12-20 \%$ of children investigated for infections of the urinary tract and is then almost always associated with vesicoureteric reflux. 'It is a major cause of hypertension and end stage renal disease and may give rise to complications during pregnancy. ${ }^{23}$ Though vesicoureteric reflux may resolve spontaneously or be corrected surgically, renal scarring is irreversible and the consequent effects can be avoided only if the process of scarring is prevented initially. There are few detailed reports of the formation of new scars, ${ }^{+10}$ possibly because they develop early in childhood, when urinary tract infections are easily overlooked and left untreated. Furthermore, in older children the urinary tract is often not investigated until infection has recurred several times, by which time renal scarring may well be established. As the numbers identified at any one centre are small, a collaborative study was undertaken to examine in detail the circumstances associated with the formation of new renal scars.

\section{Patients and methods}

In 1977 paediatricians, surgeons, and radiologists with an interest in urinary tract infections were invited to participate in a study of renal scars detected radiologically either in kidneys that were initially normal or in new areas of previously scarred kidneys. Colleagues in 23 centres agreed to collaborate. The children included in the study thus formed a group whose selection depended on the record systems of hospitals, the availability of early radiographs, clinical data, and memory recall; some were identified during a prospective search. A new scar was defined as the development of a caliceal deformity with thinning of the overlying parenchyma in an area of kidney considered to be normal in the previous intravenous urogram (figure (top and middle)). Children were accepted into the study when three independent observers agreed that new scarring had taken place. All available clinical data were then extracted. Children excluded were those who had solitary, duplex, or horseshoe kidneys, in whom confusion with dysplasia could have arisen and also those with stones or mechanical, neuropathic, or postoperative obstruction. Some children whose intra- 
venous urograms had originally been reported as normal were excluded because early films showed unequivocal evidence of scarring. Progression of existing scars (figure (bottom)) was also noted in many of the films we examined.

We expressed the age at scarring as the child's age at the time of the last intravenous urogram before the development of a new scar. In several films we came to recognise minimal changes such as a reduced nephrogram but without morphological deformity at the site where scarring later developed, suggesting that the inflammatory process had already begun.
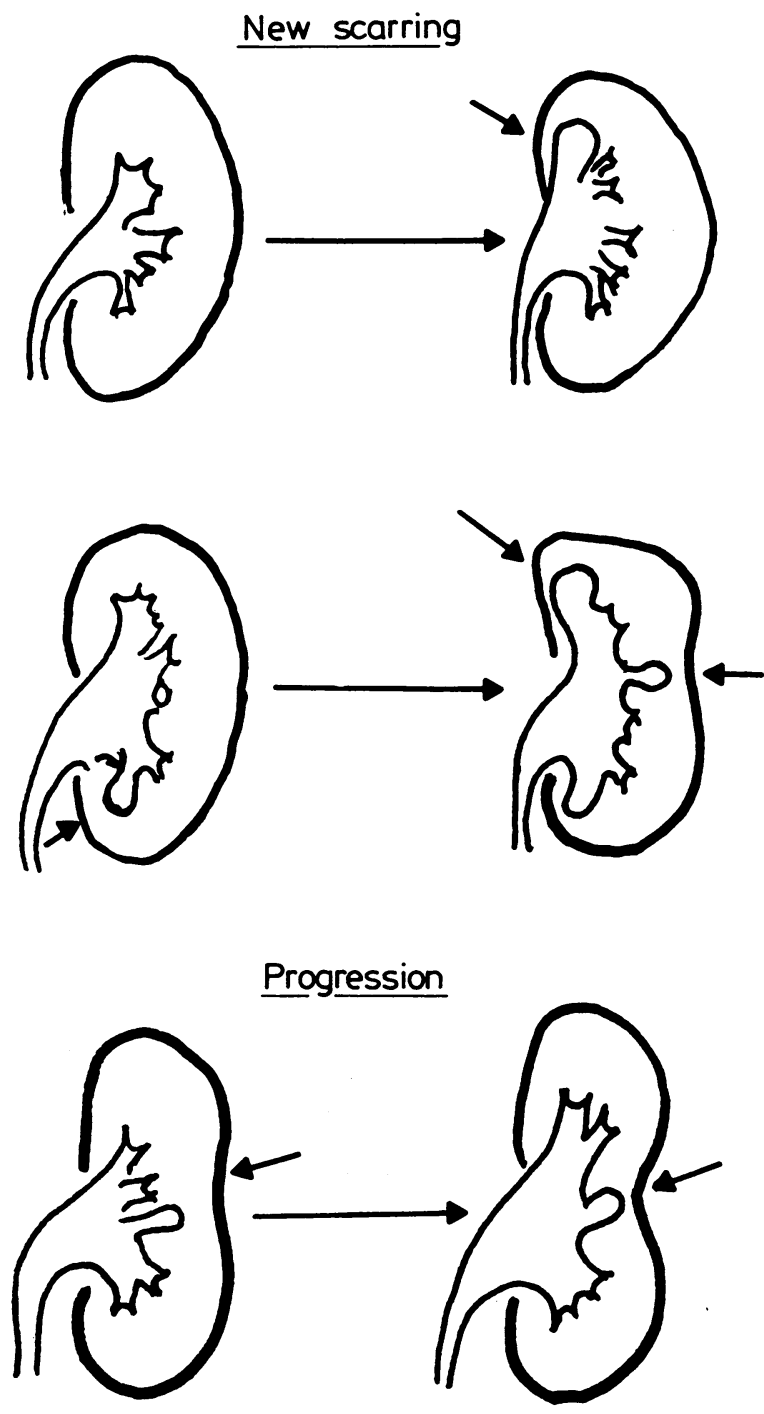

Differences between new scars and progression are shown diagrammatically above. Top: new renal scar developing in a previously normal kidney; middle: new scars in new areas of a previously scarred kidney; and bottom: progression of an existing scar resulting from fibrosis and continuing contraction of the scar with compensatory growth of surrounding normal tissue.

As the technique of cystography varied in different centres a simple grading for reflux was used: I, minimal and not reaching the kidney; II, up to the kidney without dilatation of the ureter or renal pelvis; and III, up to the kidney with dilatation of the ureter or renal pelvis.

\section{Results}

We examined serial intravenous urograms from 120 children aged from two weeks to 12 years seen between 1960 and 1982 . New scars had developed in 87 kidneys of 74 children (eight boys and 66 girls). Fifty eight children had had normal kidneys initially; in 46 the new scarring was unilateral, in 12 bilateral. Thirteen children had had unilateral renal scarring initially. In four of these the new scar developed in the contralateral, previously normal kidney. Three children had had bilateral scarring initially and developed further scarring. Thus 74 initially normal kidneys became scarred, and further scars developed in 13 already scarred kidneys. Forty were right kidneys and 47 left kidneys. Three children had bilateral scarring on entry to the study and 19 at the end of the study.

Ureteric reimplantation was carried out in 28 children, six of whom had presented with established scarring. In 18 children the new scars were seen before operation, and in 10 a new scar was first identified after operation, though in some an intravenous urogram had not been obtained immediately preoperatively.

\section{INFECTION}

Every child had infection of the urinary tract, which in 61 cases was due to Escherichia coli. All but one infection occurred shortly before the last intravenous urogram that did not show a new scar. Thirty six children had never been diagnosed as having an infection of the urinary tract before. The most common presenting symptoms were fever ( 57 children, with rigors in five and convulsions in 10) and abdominal or loin pain (34). Sixteen had chronic constipation, and in eight the symptoms suggested uncoordinated voiding with residual urine." The children were grouped as follows: (1) forty one with major presenting symptoms, including high fever, abdominal pain, and lower tract symptoms (most of these were admitted to hospital); (2) thirty one with mild or non-specific symptoms including low grade fever, wetting during the day or night, general ill health, feeding problems, and poor weight gain in infancy; and (3) two girls with bacteriuria identified by screening, one of whom was enuretic.

Delay in the recognition of urinary infection and in starting effective treatment was common. In 29 of the acutely ill children at least four days elapsed between the onset of the presenting symptoms and the start of appropriate treatment, due mainly to the delay in establishing the diagnosis in a febrile patient. Treatment was sometimes withheld until full microbiological reports with bacterial sensitivities were available. In 14 of the patients with mild symptoms the delay was at least two months, usually because the possibility of urinary infection had not been considered.

Repeated symptomatic recurrences of infection were recorded in 56 of the children ( 34 with major and 22 with mild presenting symptoms), and two had persistent bacteriuria, between the last "normal" intravenous urogram and the first that showed a new scar. All the new scars in previously scarred kidneys developed after either a recurrence of symptomatic infection or persistent bacteriuria.

\section{AGE AT SCARRING}

The children's age at the time of the last intravenous urogram without a new scar in 87 kidneys ranged from 3 months to 9 years (mean 4.4 years) (table I). Seventy five kidneys were initially unscarred, and in 12 some scarring was already present.

TABLE I-Age at which new scarring was detected in previously normal and scarred kidneys

\begin{tabular}{lrrrrrrrrrrr}
\hline & \multicolumn{11}{c}{ Age (years) } \\
\cline { 2 - 11 } & -1 & -2 & -3 & -4 & -5 & -6 & -7 & -8 & -9 & -10 \\
\hline $\begin{array}{l}\text { Kidneys } \\
\text { Previously normal }\end{array}$ & 10 & 5 & 8 & 15 & 7 & 11 & 11 & 2 & 3 & 2 \\
\hline
\end{tabular}

Only in children older than 7 years did the number of new scars decline, and one third of the kidneys that developed new scars were still normal at the age of 5 years. Thirty four of the children were aged 5 years or over when the new scar developed. The mean interval between the last intravenous urogram without a new scar and the first showing new scarring was $2 \cdot 7$ years (range 4 months to 5 years 10 months), and the mean age at which a new scar was first detected was $7 \cdot 1$ years (range $1-14$ years).

\section{VESICOURETERIC REFLUX}

Vesicoureteric reflux was seen in 67 children ( 72 kidneys) with new scars. In six children reflux was seen only in the contralateral ureter; in five children (seven kidneys) cystography was delayed for two to five years after the first intravenous urogram and reflux could have stopped during this interval; in one child cystography was not completed. In only one child did a technically satisfactory cystogram carried out immediately after presentation show no reflux. No intrarenal reflux was observed. There was a 
greater tendency for scarring to develop with more severe reflux, but new renal scars developed with all grades of reflux (table II).

The extent of new scarring varied from a single or several new scars to "global" scarring affecting most of the kidney. Table II shows the relation of the maximum observed reflux in the associated draining ureter to the scarring: gross reflux was associated with 11 of the 16 kidneys with extensive

TABLE II-Maximum observed grade of vesicoureteric reflux related to extent and development of new scarring in 87 kidneys

\begin{tabular}{ccccc}
\hline $\begin{array}{c}\text { Maximum } \\
\text { observed grade } \\
\text { of reflux }\end{array}$ & $\begin{array}{c}\text { Total } \\
\text { No of } \\
\text { kidneys }\end{array}$ & \multicolumn{4}{c}{ No of new scars/kidney } \\
\cline { 3 - 5 } & $15^{\star}$ & 9 & $2-3$ & Global \\
\hline 0 & 11 & 9 & 5 & 1 \\
I & 25 & 17 & 1 & 1 \\
III & 36 & 17 & 5 & 3 \\
\hline Total & 87 & 52 & 19 & 16
\end{tabular}

*In seven ureters the first micturating cystourethrogram was delayed for more than two years.

scarring. In one instance, where no reflux was shown, the initial cystogram was performed five years after the last normal intravenous urogram. Eleven of the 14 children who developed global scarring had severe symptomatic infections, and treatment was delayed in eight of them; six were aged 4 or over on presentation.

\section{MANAGEMENT}

Management of these children varied widely, and many were not followed up initially but were referred again at a later date. Only 12 of the children who developed new scarring had regular antibacterial prophylaxis. Twenty eight children underwent ureteric reimplantation, one had a nephroureterectomy, and one received a renal transplant after dialysis. Twenty two children had important social problems that clearly affected compliance. These included a disrupted family background; parental illness or death; coming from a family that often moved because the father was in the services; and being in care.

\section{Discussion}

Reports about the development of new scars have been limited, ${ }^{5.10}$ and this collaborative study brought together information on the new scars observed in a number of different centres, thus comprising the largest series so far. It confirms that both urinary infection and vesicoureteric reflux are central to the pathogenesis of renal scarring in children.

Urinary tract infection occurred in every child and all had symptoms, except for two schoolgirls with bacteriuria identified by screening. The fact that in $60 \%$ of the children recognition of infection and subsequent treatment were delayed, so that some were febrile with urinary infection without antibacterial cover for many days confirms the experience of Winter et al.$^{10}$ Not surprisingly, treatment and follow up varied over the 22 years of the study and much of the management practised earlier would now be regarded as unsatisfactory. Thus few of the children with vesicoureteric reflux in this series received continuous prophylaxis even though most had recurring infection. The relation between recurrent infection and new scarring is difficult to establish, although in children with reflux the probability of scarring being seen on presentation is twice as great in those with a history of two or more symptomatic infections than in those with less than two. ${ }^{12}$ Recurrent infections in children with reflux can be prevented by prophylactic chemotherapy. ${ }^{1314}$ Fresh scarring does not occur in these children, whereas $20 \%$ of children with reflux who received intermittent short courses of treatment for recurrent infection developed new scars. ${ }^{15}$ All the patients in this study who developed new scars in previously scarred kidneys had either persistent bacteriuria or recurrent infections treated only with short courses of antibacterial treatment and not by continuous prophylaxis. Clearly, treatment of symptomatic urinary infection should be started immediately after a sample of urine has been collected and not delayed until the final results have been obtained from the laboratory. Moreover, primary treatment should be followed by low dose prophylaxis until investigation is undertaken.

A new scar was occasionally found radiologically after a period of carefully supervised and successful prophylactic chemotherapy, and this parallels the observation that new scars may develop even when successful reimplantation follows shortly after the presenting infection. ${ }^{16}$ These two related observations may be explained by renal inflammation being established at the time of the first intravenous urogram but not having progressed sufficiently to produce clearly defined morphological changes visible in the radiographs. Neither prophylaxis nor surgical reimplantation can be expected to prevent scarring once these changes become irreversible, emphasising once again the need for prompt treatment of the initial infection. In some of the $x$ ray films we examined minor changes in the first intravenous urogram could be identified with hindsight at the sites where formation of scars became subsequently obvious. Scanning using dimercaprol labelled with technetium-99m (DMSA) may be able to detect with greater sensitivity those children with inflammatory parenchymal changes at presentation, ${ }^{17}$ in whom the progression to a scar or resolution may be documented subsequently.

The Birmingham study group that compared children with vesicoureteric reflux managed medically and surgically found no significant difference in the development of new scars between the two treatments. ${ }^{18}$ The group concluded that reflux nephropathy may be prevented only when a non-invasive method is found to diagnose vesicoureteric reflux before the onset of infection. The group also stated that with the imaging techniques used it could not exclude the possibility that scarring had started before entry to the study. Ransley and Risden showed in piglets that new scarring in an infected refluxing model can be modified or prevented if effective antibacterial treatment is started within one week after the onset of infection. ${ }^{19}$ We believe that rapid treatment of the presenting infection may reduce the risk of subsequent formation of scars.

Vesicoureteric reflux was seen in 68 of the 69 children who had a satisfactory micturating cystourethrogram at the time of the first intravenous urogram, and in general scarring was more extensive in children with severe grades of reflux. ${ }^{20}$ It is clear, therefore, that in this study, in which children with obstruction were excluded, reflux and infection of the urinary tract were the major contributory factors to the development of new scars. New scarring continued to occur until at least the age of 10 years. It has been widely accepted that scarring tends to develop in infancy and young children, ${ }^{21}$ and this is supported by prospective studies ${ }^{22}$ and surveys of bacteriuria in schoolgirls. ${ }^{23}{ }^{24}$ The corollary that scarring does not occur in older children is clearly incorrect. We found that it was less common after the age of 7 , but one third of the kidneys in which new scars developed were normal at the age of 5 . A child with normal kidneys and vesicoureteric reflux at the age of 5 may thus still be at risk of developing renal scars if exposed to the combination of reflux and inadequately treated infection.

To minimise the possibility of the formation of new scars in either normal or previously scarred kidneys we recommend that a child presenting with symptomatic urinary infection for the first time, even in later childhood, or who suffers further infections after earlier presentation, should receive prompt antibacterial treatment. This should be followed by prophylactic chemotherapy until the underlying cause of the infection has been determined.

This study was generously supported by a grant from the National Kidney Research Fund.

We thank many colleagues in the hospital groups listed below who collaborated in the study. We also thank the paediatricians and general practitioners, who kindly provided information and access to the children's records. In particular we thank Dr Richard White, Dr Robert Postlethwaite, Mr Robert Whitaker, Dr Roy Astley, Dr Ivan Hyde, Dr Kate Verrier-Jones, Dr Simon Meller, Mr Patrick Smith, and Mrs Brenda Danby. We alsu thank Mrs Trudy Clark and Mrs Susan Watts for their secretarial help.

Children included in this study were seen in hospitals in Birmingham, Bristol, Cambridge, Cardiff, Carshalton, Dundee, Hastings, Leeds, Manchester, Nottingham, Portsmouth, Reading, Southampton, Sutton Coldfield, and Swindon. The hospitals participating in London were Barnet; 
The Hospitals for Sick Children; Guy's; Northwick Park; Queen Elizabeth's, Hackney; the St Peter's Hospitals; University College; and the Whittington.

\section{References}

1 Smellie JM, Normand ICS. Bacteriuria, reflux and renal scarring. Arch Dis Child 1975;50:581-5. 2 Wallace DMA, Rothwell DL, Williams DI. The long term follow-up of surgically treated vesicoWallace DMA, Rothwell DL, Williams DI.
ureteric reflux. Br $\mathcal{J}$ Urol 1978;50:479-84.

3 Kincaid-Smith P, Becker GJ. Reflux nephropathy in the adult. In: Hodson CJ, Kincaid-Smith P, eds. Reflux nephropathy. New York: Masson, 1979:21-8.

4 Smellie JM, Normand ICS. Reflux nephropathy in childhood. In: Hodson CJ, Kincaid-Smith P, eds. Reflux nephropathy. New York: Masson, 1979:14-20.

5 Rolleston GL, Maling TMJ, Hodson CJ. Intrarenal reflux and the scarred kidney. Arch Dis Child 1974;49:531-9.

6 Filly R, Friedland GW, Govan DE, Fair WR. Development and progression of clubbing and scarring in children with recurrent urinary tract infections. Radiology 1974;113:145-53.

Smellie JM, Edwards D, Hunter N, Normand ICS, Prescod N. Vesico-ureteric reflux and rena scarring. Kidney Int 1975;8:S65-72.

8 Shah KJ, Robins DG, White RHR. Renal scarring and vesico-ureteric reflux. Arch Dis Child 1978;53:210-17.

9 Heale WF, Ferguson RS. The pathogenesis of renal scarring in children. In: Kass EH, Brumfit W, eds. Infections of the urinary tract. Chicago: University of Chicago Press, 1978:201-4.

10 Winter AL, Hardy BE, Alton DJ, Arbus GS, Churchill BM. Acquired renal scars in children. $J$ Urol 1983;129:1190-4.
11 Koff SA. Bladder sphincter dysfunction in childhood. Urology 1982;19:457-61

12 Smellie JM, Normand ICS, Katz G. Children with urinary infection: a comparison of those with and those without vesico-ureteric reflux. Kidney Int 1981;20:717-22.

13 Smellie JM, Grüneberg RN, Leakey A, Atkin WS. Long-term low-dose co-trimoxazole in prophylaxis of childhood urinary tract infection: clinical aspects. Br Med $\mathcal{F}$ 1976;ii:203-6.

14 McKerrow W, Davidson-Lamb N, Jones PF. Urinary tract infection in children. Br Med $\mathcal{J}$ 1984;289:299-303

5 Smellie JM, Edwards D, Normand ICS, Prescod N. The effect of vesico-ureteric reflux on renal growth in children with urinary tract infection. Arch Dis Child 1981;56:593-600.

16 Lenaghan D, Whitaker JG, Jensen F, Stephens FD. The natural history of reflux and long term effects of reflux on the kidney. $\mathcal{I}$ Urol 1976;115:728-30.

17 Merrick MV, Uttley WS, Wild SR. The detection of pyelonephritic scarring in children by radioisotope imaging $B r \mathcal{J}$ Radiol 1980:53:544-56.

18 Birmingham Reflux Study Group. Prospective trial of operative versus non-operative treatment of

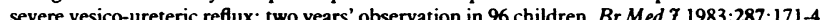

Revere Vesico-urenic reflux: (wo years' observation in 96 children. BrMed $1983,287.171-4$. the early pyelonephritic scar. Kidney Int 1981;20:733-42.

20 Olbing $\mathbf{H}$. Reflux grade at first presentation and the risk of renal scarring. In: Brodehl J, Ehrich JHH, eds. Paediatric nephrology. Berlin: Springer Verlag, 1984:317-20.

21 Winberg J, Bollgren I, Källenius G, Möllby R, Svenson SB. Clinical pyelonephritis and focal rena Winberg J, Bollgren I, Källenius G, Möllby R, Sven
scarring. Pediatr Clin North Am 1982;29:801-14.

22 Randolph MJ, Morris KE, Gould EB. The first urinary tract infection in the female infant. $J$ Pediatr 1975;86:342-7.

23 Cardiff-Oxford Bacteriuria Study Group. Sequelae of covert bacteriuria in schoolgirls. A four year follow up study. Lancet 1978;i:889-93.

24 McLachlan MSF, Meller S, Verrier-Jones ER, et al. The urinary tract in schoolgirls with covert bacteriuria. Arch Dis Child 1975;50:253-6.

\title{
Computer assisted shared care in hypertension
}

\author{
J C PETRIE， O J ROBB， J WEBSTER， A K SCOTT，T A JEFFERS， M D PARK
}

\begin{abstract}
A computer assisted shared care scheme for the long term management and follow up of hypertensive patients has been developed in the Grampian Region. The scheme aims at facilitating the exchange of clinically important information between doctors and at achieving target levels of blood pressure with treatment in patients at highest risk of cardiovascular events.

The shared care scheme has been well received by the local practitioners. Two hundred and fifty seven patients $(18 \%)$ of 1426 patients under current long term follow up are assigned to follow up in the hospital aspect of the scheme. At the most recent visit $32 \%$ of patients in the hospital aspect and $10 \%$ of 1169 patients in the general practice aspect had blood pressure recordings above the target levels of $160 / 95 \mathrm{~mm} \mathrm{Hg}$.

The stratification of patients formerly attending hospital clinics into grades of risk has rationalised our follow up procedures to allow the specialist resources to be freed and concentrated on those patients at highest risk and with the most complex problems. This computer assisted patient records system could be applied to other groups of high risk patients in whom long term follow up and surveillance are necessary-for example, patients with diabetes mellitus-and has implications for optimising and monitoring the delivery and outcome of care without overwhelming limited hospital resources.
\end{abstract}

Department of Therapeutics and Clinical Pharmacology, University of Aberdeen and Medical Computing Centre, Grampian Health Board, Aberdeen Royal Infirmary, Foresterhill, Aberdeen AB9 2ZB

J C PETRIE, FRCP, reader

O J ROBB, MRCP, research registrar

J WEBSTER, MD, MRCP, senior lecture

A K SCOTT, MD, MRCP, lecturer

T A JEFFERS, MRCP, honorary senior lecturer

M D PARK, senior systems designer

Correspondence to: Dr J C Petrie.

\section{Introduction}

The control of blood pressure during treatment is an important predictor of the occurrence of cardiovascular events. ${ }^{12}$ An important problem in the care of hypertensive patients is that higher risk patients may be overlooked, inadequately treated, and ineffectively followed up among the mass of lower risk patients. Nevertheless, both groups need some form of long term surveillance.

We have developed a computer assisted patient record system whose principal aim is to improve and facilitate the transfer of clinically important information between doctors in hospital and general practice. ${ }^{3}$ We now report an extension of the patient record system to the long term shared care follow up of patients referred to our clinic for assessment of raised levels of blood pressure.

\section{The scheme}

The catchment area of the Aberdeen blood pressure clinic includes the population of the north east of Scotland, Orkney, and Shetland (about 500000 ) and is served by over 250 principals in general practice. All patients who are referred to the clinic undergo assessment before they are entered in the computer assisted shared care scheme. ${ }^{4}$ They include patients with borderline or transient rises of blood pressure, with accelerated or refractory hypertension, or with renal, cardiovascular, and cerebral complications of hypertension, or adverse reactions to drug treatment.

Some 1631 patients have been registered since the start of the shared care scheme in 1980. There have been 64 deaths (4\%). At present the cohort under follow up is 1426 patients. Some $18 \%$ ( 257 patients) are allocated to the hospital aspect of the scheme. The balance of patients are assigned to the general practice aspect (1169 patients), in clinical research studies (92 patients), have left the area (44 patients), or have been excluded from regular follow up because of repeated non-attendance (five patients).

A follow up appointment is scheduled in either the general practice or hospital aspect of the scheme depending on the severity of the rise of blood pressure, associated risk factors, concurrent diseases, or remote domicile. 